\title{
Implications of Climate Change for Human Health in Nigeria
}

\author{
I. J. Ekpoh*, B. J. Bassey \\ Department of Geography and Environmental Science, University of Calabar, Calabar, Nigeria \\ Email: imyjay55@yahoo.com
}

\begin{abstract}
The current climate change is different from previous ones in earth history because it is caused by human activities and is more dramatic in the pace of change. The major objective of the study was to consider the relationships between climate change, air pollution and human health. To achieve the objective of study, the study adopted the theoretical approach by relying heavily on the review of previous studies in the relevant fields of the subject matter. Accordingly, empirical studies on the state of climate change in Nigeria were extensively reviewed, together with the implications of climate change for human health and comfort. The study noted that climate change has raised the mean global temperature by about $0.6^{\circ} \mathrm{C}$, which has caused global warming and is aggravating existing air pollution problems. The direct implication of climate change for human health and comfort is the increased incidence of heat stress and respiratory diseases. The study suggested the adoption of a strategic planning approach in building capacity for coping with climate change-health issues.
\end{abstract}

Keywords: Climate change, global warming, air pollution, heat waves, respiratory diseases.

\section{Introduction}

Significant changes in global climate are not strange in Earth's history. From ancient times, early naturalists and philosophers theorized on a possible climate change. For instance, Theophratus, a pupil of the famous Greek philosopher, Aristotle (384-322 B.C), speculated that lands became warmer when the clearing of forest exposed them to sunlight. Equally, many Renaissance scholars, including Vitruvius, were of the opinion that deforestation, irrigation and grazing had effects on the local weather around the Mediterranean, and in particular, the Anatolian Peninsula along the Aegean Sea. By the late $18^{\text {th }}$ century, the works of naturalists such as James Hutton, Jean-Pierre Perraudin, Jean de Charpentier and Ignaz Venetz led people to think about glaciers and climate change. For instance, Louis Agassiz developed the theory of ice age, when glaciers covered Europe and much of North America, although the idea of a possible climate change began in the early $19^{\text {th }}$ century when ice ages and other natural changes in paleoclimate were first suspected and the natural greenhouse-effect first identified. Many other theories of climate change were advanced, involving emission from volcanism and solar variation (Sunspot) [1].

Since those early days, scientists have used several methods, including historical records, tree ring analysis (dendrochronology), pollen grain analysis (palynology), oxygen isotope ratios, glacial tills, sea planktons, radiometric dating of rocks and fossils, to reconstruct a possible account of Earth's history. Going by the geological time-scale of earth's history, it has been shown that the Earth had experienced five major climate change episodes from the Pre-Cambrian times, most of which lasted for millions of years. For instance, it took the Earth's climate about 2 million years to change from the last Ice Age which started during the Pliocene Epoch of the Tertiary Era to the current Holocene-Interglacial warming of the Quaternary Era. Earlier climate change episodes in Earth's history even took longer durations with severe consequences for plants and animals. For instance, dinosaurs, which flourished on earth from the Jurassic period some 200 million years ago, were wiped out and became extinct during the Pleistocene ice age (climate change), some two million years ago. Numerous other animals and plants that could not adapt to the ice age were equally made extinct. Thus, climate change is a very serious environmental phenomenon that should not be taken lightly. 
In the climate change business, everyone is a stakeholder because it is a global problem that does not recognize national boundaries, race or creed. Thus, any effort to educate the public on the nature of the phenomenon, the impacts and possible mitigation/adaptation options, should be commendable. This is so because appropriate knowledge that makes us to adopt even small changes in our daily lives can make a difference between life and death.

\section{The Current Climate Change}

The current climate change which started since the late 1960s has occurred at an alarming speed and is attributed largely to human activities. The history of civilization has some correlation with the current climate change because the early humans were largely hunters and gatherers, who later developed into agrarian farmers, and then to crowded communities in huge industrial megalopolises [2]. Equally, a careful examination of the world population has also revealed a close association with the current climate change. For instance, by 1800, the entire world population was about 1 billion. After 127 years, the world population rose to 2 billion in 1927. From that time, the increase in world population became very rapid as seen in the following sequence: 3 billion by 1960; 4 billion by 1974; 5 billion by 1984; 6 billion in 1999 and 7 billion by 2011 [3]. As populations grow and communities try to improve their living standards, with its concomitant modernization of urban and rural environments through the provision of infrastructure, there is always the pressure on earth's resources, especially fossil fuel and forest resources. Thus, urbanization and the growing demand for goods and services have brought an enormous increase in industrial activities and consequently a significant utilization of mineral and energy resources, with walloping emissions of greenhouse gases [4]. Carbon dioxide, a major bi-product of fossil fuel consumption and forest clearance has been implicated, alongside other greenhouse gases such as methane, nitrous oxide and chlorofluorocarbon, as being largely responsible for the current global warming.

\section{Global Warming}

Much of the apprehension that greeted the onset of climate change in the 1980s and 1990s has largely been put to rest, thanks to the untiring work of the Intergovernmental Panel on Climate Change (IPCC). Today it is no longer news that the earth's atmosphere is warming as a consequence of human activities, primarily fossil fuel combustion, industrial processes and deforestation, which causes the release of greenhouse gases such as carbon dioxide, methane, nitrous oxide and chlorofluorocarbons into the atmosphere. From a pre-industrial level of 280 parts per million by volume (ppmv), carbon dioxide, for instance, increased to $380 \mathrm{ppmv}$ by 2005; an increase of about 40 per cent. The projection for 2015 level of carbon dioxide in the atmosphere was put at $400 \mathrm{ppmv}$ [5]. It should be stated here that the preponderance of greenhouse gases in the earth's atmosphere is responsible for the formation of a gas layer in the troposphere called the greenhouse gas layer. It is this gas layer that has caused global warming of the earth's atmosphere, by allowing short-wave solar radiation to pass through it to the earth's surface while restricting the spaceward journey of some of the long-wave terrestrial radiation, thus causing a surplus heat budget in the lower atmosphere. Global warming has already resulted in an increase in the global mean temperature of the atmosphere by about $0.6^{0} \mathrm{C}$, and a continuation of the historical trend of greenhouse gas emissions under the "business- as-usual" scenario of human activity will lead to a further rise in air temperature throughout the $21^{\text {st }}$ century [6]. Already, current predictions from General Circulation Models (GCMs) suggest a global temperature rise of between $1.1^{\circ} \mathrm{C}$ and $6.4^{\circ} \mathrm{C}$ by 2100. Rising atmospheric temperatures mean more heat in the atmosphere. Elevated ambient temperature also translates to more misery for human beings and their economic systems. As predicted by IPCC Report [6], southern parts of Nigeria will experience more rainfall leading to severe flooding, while the northern parts of Nigeria will have increased temperature, heat stress, droughts and water shortages. 


\section{Empirical Evidence of Climate Change in Nigeria}

Electronic and print media worldwide are awash almost on a daily basis with news and images of catastrophes, damages, dislocations, disruptions and deaths caused by climate change. Therefore, the focus of this section is on scientific studies with empirical evidence. Studies have shown that Nigeria is already in the thick of climate change $[5,7,8,9,10,11,12]$. In a study that involved 30 meteorological stations and 105 years of observation, [13] carried out long-term temperature analysis and the result showed that the mean temperature for Nigeria since 1901 remained steady until the late 1960s when it started a gradual rise that has continued to the present time, in response to global warming. The experiment was repeated for rainfall in Nigeria from 1901 to 2005 and the result showed a general decline, with a loss of $81 \mathrm{~mm}$ of rainfall during the period. Another study also showed that rainfall in Sokoto for the period from 1968 to 2008 declined by 8.8 percent of the long-term (1915-2008) mean, while other rainfall characteristics such as late onset, early cessation and long breaks within the rainy season were noticed to have become more frequent [7]. A further scrutiny of instrumental data for Nigeria also revealed that climate change impact on rainfall in Nigeria did not translate to a general decline in total amount for all regions but could be quite erratic in amount and pattern of distribution from area to area. Indeed, it is this erratic nature of climate change that poses the greatest problem to planning and adaptation. As [11] observed, Nigeria's locational factor (i.e. Nigeria lies between latitudes $4^{0} \mathrm{~N}$ and $14^{0} \mathrm{~N}$; and longitudes $2^{0} \mathrm{E}$ and $14^{0} \mathrm{E}$ ) suggests perennial humid conditions in the southern states with annual rainfall of $1000 \mathrm{~mm}-2500 \mathrm{~mm}$ but exceeding $3000 \mathrm{~mm}$ in parts of the Niger Delta and the southeast corner, while the extreme drought-prone parts may receive anything from $250 \mathrm{~mm}$ to $700 \mathrm{~mm}$. Superimposed on this spatial diversity are the inter- and intra-seasonal variations which are common due to regular transient atmospheric flow patterns and systems and are responsible for localized and regional variations exceeding 50 percent. For instance, many coastal locations in Nigeria such as Lagos, Ibadan, Uyo and Calabar have received excessive rainfalls recently which resulted in historic floods that caused substantial loss of lives and property, while locations in northern Nigeria had deficit rainfall budget $[14,15,13,16]$. Thus, Nigeria is considered to be one of the most climatologically vulnerable countries in Sub-Saharan Africa with respect to climate change.

A study conducted by [17] on annual rainfall trends and fluctuations in Sudano-Sahelian Ecological Zone of Nigeria, which involved 8 meteorological stations, with rainfall data from 1949 to 2008, used the Cramer's test to compare means. The result of the study revealed that there was a change towards wetter conditions in the last 30 years. Other studies also showed that the number of rainy days during the last 30 years have dropped by 53 percent in north-eastern parts of Nigeria while the coastal areas have experienced a drop of about 14 percent in the number of rainy days. Furthermore, the areas experiencing double rainfall maxima have shifted southwards while the short dry season called "August Break" is being experienced more in July as against the usual occurrence in August prior to 1969 [13, 18]. While the desiccation which started in the Sahel of West Africa in the late 1960s is implicated as being responsible for the recession of Lake Chad from 25,000 km² in 1963 to a paltry $1,250 \mathrm{~km}^{2}$ in recent times, a loss of about 90 percent of its previous size [7, 8, 19, 9], the 2010 Sokoto floods which destroyed Goronyo dam and swept away the only bridge linking Usuman Danfodio University main campus to Sokoto town was attributed to an extreme rainfall event caused by climate change. These paradoxes clearly confirm the uncertain and highly unpredictable nature of the anthropogenetically-induced $21^{\text {st }}$ century Climate Change. Floods in southern Nigeria used to have rhythms of 25 to 30 years cycle. However, since the late 1960s which signaled the beginning of significant climatic disturbances in subSaharan Africa, the recurrence of floods has become a game of lottery with no predictable cycle. From these observations, it sounds reasonable to admit that climate change has already altered the climate of Nigeria substantially.

\section{$5 \quad$ Climate Change and Human Health}

After over 10,000 years of stability, the chemistry of the earth's atmosphere is changing rapidly due to human activities. Since ancient days, the long-term good health of a population depended on the continued stability and functioning of the biosphere's ecological and physical system, often referred to as life-support system. The weather and climate of a place constitute an integral part of that complex life- 
support system, while the mechanics of humans, like every other living thing including plants and animals, depend upon air and other fibers of the natural environment for sustainability [20, 21]. Therefore, climate change due to global warming, will be disastrous for human health and comfort since it will alter the normal composition of the earth's atmosphere upon which life depends.

Mankind is both the driver of climate change, as well as, the recipient of the impacts thereof. Unsustainable exploitation of the earth's resources, which causes huge emissions of greenhouse gases, has affected the energy budget of the earth with significant impact on climate. Conversely, rising temperatures, changing patterns of precipitation, increased frequency of storms, rising sea levels (all of which are products of climate change), substantially influence the capacity of societal development. However, the character of the impact of climate change on a particular aspect of societal development do depend in part on the nature and intensity of climate change, and in part, on the nature of the society in terms of its level of resilience or vulnerability. Nigeria's First National Communication (NFNC), under the United Nations Framework Convention on Climate Change (UNFCCC), has identified the potential areas of human development that are already impacted by climate change to include: Health, Agriculture, Water Resources, Energy, Transportation, Settlement, Construction Industry, Fisheries, Tourism, Out-Door Recreation, Pastoralism, Ecosystem, etc. [22, 15].

The interaction between climate and human health/comfort is probably the most obvious of the relationship between climate and society. For instance, when it rains, we look for an umbrella or a raincoat, or run for a shelter. Equally, when the weather is hot, we look for shade or something to fan our body, or even drink a lot of water due to increased perspiration. During the "harmattan" season, we find the air very dry and dusty, with high incidence of cracked lips, cough and catarrh. Ambient air temperature is elevated and rooms become so hot that we suffer from profuse sweating and heat rashes. These are some of the ways in which we interact directly with the weather on a regular basis, even without climate change. With climate change, the scale of climate-health problems has expanded from micro-level to macro- or global level, and the impacts are intense, and they are both direct and indirect. The direct impacts concern issues of heat stress and heat waves; cold and frost bites. The indirect impacts are those health problems that arise as collateral consequences from climate change impact on our ecological and economic systems.

\subsection{Direct Impacts}

Hot weather due to climate change will reduce human comfort through profuse sweating, heat rashes, restlessness and other heat-related illnesses. Heat waves will increase the risk of excess morbidity and mortality. Hot working environments created by climate change will reduce human ability for physical or mental tasks and, prolonged exposure to heat may lead to heat exhaustion or heatstroke [21]. For instance, epidemiological studies of death during heatwave have revealed that the most obvious health effect is directly from the heat itself. As reported by USEPA [23], heat wave killed more than 700 people in Chicago area alone in July 1995. With increased and intensified heat waves from climate change, many more people will suffer from heat stroke, heart attack and other ailments associated with elevated heat. In terms of cost, the United Nations has estimated that it will cost between $\$ 70$ and $\$ 100$ billion a year by 2030, to meet the health needs of the world [24].

Higher temperatures in the cities (called urban heat island) will lead to an increase in the ground-level concentration of noxious gases and smoke particles, which will accelerate chemical reactions that generate other pollutants, thereby increasing air pollution problems. Elevated air temperature and air pollution are well recognized by scientists as serious health concern because breathing polluted or dirty air often leads to increased probability of heart attacks, respiratory diseases, lung cancer and cardiovascular disorders. According to USEPA [23], a study conducted on air quality and human health impacts of greenhouse gas emissions globally revealed the following frightening statistics: 6,500 premature deaths, 4,000 hospital admission cases for respiratory diseases, 3,000 hospital admission cases for cardiovascular diseases, 3,500 asthma attacks, 2,000 asthma-related emergency room visits, and an unquantified reduced lung function growth rate in children. Chronic exposure of people to air pollution increases the prevalence of cough, phlegm, rhino-rhea, dry/sore throat, sinus congestion, wheezing, eye irritation and bronchitis [25]. Against the backdrop of the 2007 forecasts by the Inter-Governmental Panel on Climate Change (IPCC), climate change will have wide-ranging and most adverse impacts on human health, with significant loss of lives. 
Vector borne diseases (VBD) are presently posing major public health threats in many parts of the world, especially sub-Saharan African. They are transmitted by insects or other arthropods which include malaria, onchocerciasis, schistosomiasis, trypanosomiasis and dracunculiasis, to name but a few. As climate change increases global temperatures, regions that hitherto were free of VBDs due to cold climates, will see migration of these vectors into new regions with elevated temperatures. Climate change-related heat could allow insects and pests to migrate up to 550 kilometres from their endemic regions, with the result that 50 to 80 million cases of malaria annually will be added to the current level [26]. The destruction of stratospheric ozone (ozone depletion) will lead to increased ultra-violet radiation reaching the earth, thereby raising the incidence of skin cancer, cataracts and river blindness.

\section{$5.2 \quad$ Indirect Impacts}

Heavy Rainfalls and Flooding: Heavy rainfalls that are induced by climate change would cause a lot of chaos to the transportation sector through reduced visibility and slippery surfaces of roads/aircraft runways, which may lead to increased automobile/aircraft accidents that can result in bodily injury or death. Already, heavy rainfalls have caused severe flooding in many parts of the world, including parts of southern Nigeria such as Calabar, Uyo, Bayelsa, Ibadan and Lagos, which have had more than a fair share of devastating floods. Flooding also causes dislocation of communities with attendant problems of potable water scarcity, poor sanitation, typhoid, dysentery, cholera and related diarrheal diseases. During floods, soil wash and sewage systems' overflow, could contaminate water sources with grave health consequences for consumers.

Melting Ice and Sea Water Intrusion: Elevated global mean temperature due to climate change is expected to melt a significant proportion of the Arctic and Antarctic ice sheets which have already commenced. The melting ice will lead to sea level rise, which could cause saltwater to intrude into freshwater sources with serious health implications for coastal dwellers.

Acid Precipitation: Climate change will cause increased precipitation of atmospheric pollutants (aerosols and noxious gases) into open water supply systems such as streams and rivers with serious health implications such as high levels of bronchial and pulmonary illness, for people who depend on such water sources [18]. Another study has also shown that, ground-level Ozone, when precipitated into water sources could stimulate unusual rapid respiration in the lungs and blood stream, causing asthmalike symptoms in consumers [26].

Wind Storms: Climate change is expected to increase not only the frequency of wind storms but also their intensity. Severe windstorms such as tornadoes, hurricanes, typhoons and thunderstorms are already associated with massive deaths and property damage. Climate change induced windstorms will cause more damage and death through massive flooding of low-lying coastal areas, falling trees and power lines, direct mangling of objects (as with tornadoes). Indeed, mental health effects such as depression and anxiety have been reported after extreme weather events (tornado, hurricane or intense thunderstorm events) [21].

Drought: Drought is already a frightful phenomenon in arid and semi-arid regions of the world because it is almost synonymous with hunger and malnutrition, especial in sub-Saharan Africa. Climate change heat and desiccation may extend the influence of drought from semi-arid regions into previously wet, productive regions of the earth, with the attendant consequences of crop failures, food shortages, hunger and malnutrition. Many semi-arid regions of the world may also transit into deserts proper with serious dislocation of people or complete annihilation of human populations.

\section{The Way Forward}

Addressing climate change and its impacts on society is not a simple task. It requires that all hands must be on deck. Therefore, responding to climate change from both policy level and house-hold level is required to combat the menace of this phenomenon. Specifically, to deal with the health effects of climate change, the following measures are suggested:

Policy Responses: At the policy level, climate change mitigation and adaptation require strategic planning through sound policy formulation, provision of regulatory and institutional frameworks, as well as, the building of robust human and material capacities. Nigeria has many policies, strategies and plans 
that are intended to address general adaptation measures in many climate change vulnerable sectors such as agriculture, water resources, health, energy, transportation, forests and ecosystems, and coastal marine environment. However, the policy framework to align human development and climate change efforts through adaptation remain largely undeveloped in the country.

Disaster Preparedness: The health sector should be engaged in disaster preparedness activities at all levels: national, state and local or community. This is called strategic planning and it has the advantage of a robust, efficient system of response that would cater not only for the relief materials needed by the people, but also provide the strategy for tackling the underlying causes of the problem through the creation of a systematic framework of doing things. We are familiar with the way Nigeria reacts in times of adversity. The country has often resorted to "fire brigade" approach of making ad hoc plans to respond to each environmental disaster as it occurs. Thereafter, the entire crisis is swept under the carpet without attending to the underlying factors that might have caused the problem in the first instance, and there is no concerted effort to prevent a reoccurrence. The serious concern about this approach of emergency response is that it keeps the impacted community in perpetual cycle of fear, misery and poverty, while making the government to look insensitive and incompetent [15, 5]. Policy responses to the 2010, 2011 and 2012 flood disasters in Nigeria are still very fresh in our minds. The unending suffering and complaints by impacted individuals and communities can best attest to the inefficiency of emergency response system in such situations.

Vulnerability Assessments: The health sector should undertake vulnerability assessments in order to identify vulnerable areas or regions that may easily succumb to climate change impacts, for appropriate capacity building and resource allocation. This will ensure that appropriate attention is given to events as they occur.

Encourage Collaboration: It will be helpful to widen the Climate Change Actors' space by ensuring that government actors collaborate with non-government actors (NGO's, Civil Societies and Community based organizations) in the development of adaptation policies and strategies. For instance, early warning signs put forward by Meteorological Agencies should be coupled into plans of action. Thus, there should be greater synergy between weather scientists and medical/humanitarian experts.

City Planning and Building Designs: To combat the heat associated with climate change in urban centers, building designs and orientation should be made in such a way that they derive maximum benefit from natural breeze and prevailing winds. Equally, city planning should provide enough open spaces and green areas for air corridors, so as to reduce the effect of urban heat island. Artificial air cooling of homes and work places may be the ultimate solution to climate change-induced heat in cities, although this may be expensive and may put pressure on energy demand, which in itself is a climate change driver.

Tree Planting: Tackling climate change should be everyone's business and not left for government alone. As a developing nation with abundant natural resources, Nigeria can sustainably manage her forests such that they serve us today and remain for tomorrow. Massive tree planting throughout the country and, especially in areas of the country that have already been degraded, should be undertaken to tackle global warming.

End Gas Flaring: Nigeria is an oil and gas producing country. Taking appropriate steps to end gas flaring in the Niger Delta region will be a significant contribution by Nigeria towards mitigating climate change.

Household-level Adjustments: Energy conservation measures such as turning off electric lights and appliances when not in use, preferring to walk or cycle rather than driving always, planting trees and creating lawns in our surroundings; all these are house-hold level measures that individuals and groups can adopt to mitigate climate change.

Advocacy and Public Enlightenment: Many government policies succeed when the public is carried along. Climate change is such a serious issue that we cannot afford to be complacent with information dissemination. It is therefore very important that the public be informed about climate change; the science, the mitigation efforts and adaptation options.

Adequate Funding: To achieve many of the strategies listed in this section, there is the need for adequate and sustainable funding for climate change issues, especially as they relate to the health sector. We should remember the "wise saying" that "Health is wealth". 


\section{Conclusion}

This study has addressed the issue of climate change and human health. It has shown that climate change is real in Nigeria and should be taken seriously in all sectors of the economy, especially the health sector. The study is of the opinion that if we can mitigate climate change, then the negative impacts on health and other sectors of the economy would have been averted. Therefore, addressing the problem of climate change will entail a fundamental shift away from the manner in which we have been doing things in the past, to ways that will dramatically reduce emissions of carbon dioxide and other greenhouse gases. In this way, we will not only protect our health, our economy and our environment against the adverse effects of climate change, but will further guarantee a better and secure future for our children and generations yet unborn. The increasing frequency of climate change-related disasters in Nigeria, especially floods, droughts, heat stress and their associated health impacts demand that strategic plans be made to contain the menace. Our actions today will determine the health and environment that we will have tomorrow. By choosing to take appropriate actions today, we limit the damage for tomorrow. Failure to do so may result in environmental catastrophe of monumental proportion. Again, as the "wise saying" goes, "Prevention is better than cure".

\section{References}

1. J. Neumann, "Climate Change as a Topic in the Classical Greek and Roman Literature". Climate Change, vol. 7 , pp.441-454, 1985.

2. G. R. Thompson and J. Turk, "Earth Science and the Environment". Brookes/Cole, USA, 2005.

3. United Nations Population Fund, "State of World Population 2012". http:/www.unfpa.org, 2012.

4. C. K. Ajaero, T. I. Akukwe and G. C. Asuoha, "Climate Change: Concepts and Issues". In Anyadike, R.N.C., Madu, I.A. and Ajaero, C.K. (Eds) Climate Change and the Nigerian Environment. Jamoe Publishers Nigeria, Enugu, Nigeria, 2010.

5. I. J. Ekpoh, "Climate Change and Recent Severe Flooding in Uyo, Akwa Ibom State, Nigeria". Global Journal of Social Sciences, vol. 14, pp 23-33, 2015.

6. IPCC, "Climate Change 2007: Synthesis Report". FAR of IPCC. Geneva, Switzerland. pp.104, 2007.

7. I. J. Ekpoh and E. Nsa, "Extreme climatic variability in north-western Nigeria: an analysis of rainfall trends and patterns". Journal of Geography and Geology, vol. 3, no. 1, pp.51-62, 2011.

8. P. A. O. Odjugo, "Quantifying the cost of climate change impact in Nigeria: Emphasis on wind and rainstorms". Journal of Human Ecology, vol. 28, no.2, pp.93-101, 2009.

9. A. Chindo and P. N. Nyelong, "Lake Chad: From mega-lake to mini-lake". Arid Wetland Bulletin, No.6, pp.24-27, 2004.

10. A. D. Mshelia, "Adaptation strategies to climate change". Journal of Energy and Environment, vol, 18, no.3, pp.74-81, 2005.

11. D. O. Adefolalu, "Climate change and economic sustainability in Nigeria". Paper presented at the International Conference on Climate Change. Nnamdi Azikiwe University, Awka, 12 - 14 June 2007.

12. N. S. Esiobu and G. C. Onubuogu, "Trends, Perceptions and Adaptation Options of Livestock Farmers to Climate Change in Imo State, Nigeria: A Multinomial Logit Model Approach". Journal of Economics and Sustainable Development, vol. 5, no. 19, pp.21-36, 2014.

13. P. A. O. Odjugo, "General overview of climate change impacts in Nigeria". Journal of Human Ecology, vol. 29, no. 1, pp47-55, 2010.

14. I. J. Ekpoh, "Recent Severe Flooding in Calabar, Nigeria: Causes, Consequences and Possible Remedies". International Journal of Sciences, vol. 3, no. 1, pp.102-105, 2014a.

15. I. J. Ekpoh, "Slow Response to Climate Change in Nigeria: need for urgent and comprehensive action". Studies in Social Sciences and Humanities, vol.1, No.2, pp.19-29, 2014b.

16. P. V. Baudi and A. N. Ahmed, "The impacts of wind related hazards in Southern Cameroon". Journal of Physical Sciences, vol.3, no.2, pp.82-88, 2006.

17. I. B. Abaje., O. F. Ati and E. O. Iguisi, "Recent Trends and Fluctuations in the Sudano-Sahelian Ecological Zone of Nigeria; Risks and opportunities". Journal of Sustainable Society, vol. 1, no. 2, pp.44-51, 2012. 
18. I. J. Ekpoh, "Climate, Society and Environment". St. Paul's Publishing Co. Ltd. Calabar, Nigeria, 2009.

19. A. Bomford, "Slow death of Africa's Lake Chad", BBC News, Lake Chad. http://news.bbc.co.uk/2/hi/4906692.stm, 2006.

20. A. J. McMichael, "Insights from Past Millennia into Climatic Impacts on Human Health and Survival. Proc Natl Acad Sci, USA, vol.109, pp.4730-4737, 2012.

21. L. Nerlander, "Climate Change and Health. Commission on Climate Change and Development". SE 10339 Stockholm, Sweden, 2009.

22. Federal Republic of Nigeria, "Nigeria's First National Communication under the United Nations Framework Convention on Climate Change". Landmark Publications, Lagos, Nigeria, 2003.

23. USEPA, "Health Assessment Document". U. S. Environmental Protection Agency, Washington, DC 20460, USA, 2007.

24. United Nations, "Climate will cost much more than UN thinks". http:/www.newscientist.com/article/, 2009.

25. J. E. Hickson, "Air Pollution as a Climate Forcing Factor". Proceedings, Honolulu, Hawaii, 2000.

26. S. Epstein, "Trends and Temporal Variations of Major Greenhouse Gases". J. Atmos Environ Science, vol. 42, issue 38, pp.8707-8716, 2007. 